\title{
Establishment of content criteria of marker compounds through the monitoring of Achyranthis Radix collected from Korea and China
}

\author{
Dae Hyun Kim, Sang Hyuk Kim, Yu Seon Jang ${ }^{1}$, Min Chul Shin, Chu Van Men, \\ Young Keun Lee ${ }^{2}$, Mi Hee $\mathrm{Woo}^{3, \star}$ and Jong Seong Kang ${ }^{\star}$ \\ College of Pharmacy, Chungnam National University, Daejeon, Korea \\ ${ }^{1}$ Institute of Drug Research \& Development, Chungnam National University, Daejeon, Korea \\ ${ }^{2}$ Daejeon Health Sciences College, Daejeon 300-711 Korea \\ ${ }^{3}$ College of Pharmacy, Catholic University of Daegu, Gyeongsan 712-702, Korea \\ (Received March 16, 2012; Revised July 30, 2012; Accepted July 30, 2012)

\section{한국 및 중국 지역에서 수집된 우슬의 모니터링을 통한 지표성분의 함량기준 설정} \\ 김대현 · 김상혁 · 장유선 ${ }^{1}$ - 신민철 · 주반멘 · 이영근 ${ }^{2}$ · 우미희 ${ }^{3, \star ~ · ~ ㄱ ㅏ ㅇ ㅈ ㅗ ㅇ ㅅ ㅓ ㅇ \star ~}$ \\ 충남대학교 약학대학, ${ }^{1}$ 충남대학교 의약품개발연구소, \\ ${ }^{2}$ 대전보건대학, ${ }^{3}$ 대구가톨릭대학교 약학대학 \\ (2012. 3. 16. 접수, 2012. 7. 30. 수정, 2012. 7. 30. 승인)
}

\begin{abstract}
Two marker compounds of Achyranthis Radix, ecdysterone and inokosterone, were analyzed by HPLC on an ODS column $(250 \times 4.6 \mathrm{~mm}, 5 \mu \mathrm{m})$ with a mobile phase of $15 \%$ acetonitrile containing $0.08 \%$ formic acid at a flow rate of $1.0 \mathrm{~mL} / \mathrm{min}$ and a detection wavelength of UV $254 \mathrm{~nm}$. The method was validated by ICH guideline and applied to the monitoring of marker compounds in 93 samples of Achyranthis Radix collected at various areas in Korea and China. The new content criteria of ecdysterone and inokosterone, established using linear regression method were $0.033 \%$ and $0.020 \%$, respectively. When the new content criteria were applied to the quality control test of commercial Achyranthis Radix, $95.4 \%$ of total samples including $100 \%$ of Korean and $92.6 \%$ of Chinese samples were passed the test. Application of new content criteria could protect the Korean products and decrease the distribution of Chinese products with lower quality.

요 약: 우슬의 지표성분인 ecdysterone과 inokosterone을 HPLC방법으로 분석하였다. 이 때 ODS 컬럼과 이동상으로 $0.08 \%$ 포름산을 함유하는 $15 \%$ 아세토니트릴 용액을 사용하였고, 이동상의 유속은 $1.0 \mathrm{~mL} /$ $\min$, 검출파장은 $254 \mathrm{~nm}$ 였다. 사용된 방법을 $\mathrm{ICH}$ 가이드라인에 따라 우효성을 확인하였고, 한국 및 중 국의 각 지역에서 수집된 우슬 시료 93점에 대한 지표성분의 모니터링에 적용하였다. 직선회귀법에 의 해 산출된 ecdysterone과 inokosterone에 대한 새로운 함량기준은 각각 $0.033 \%$ 와 $0.020 \%$ 로 나타났다, 새 로운 기준을 시판되는 우슬에 적용하였을 경우 국산은 모두가 합격하였고 중국산은 $92.6 \%$ 가 합격하여 전체적 합격률은 $95.4 \%$ 였다. 새로운 기준은 지표성분의 함량이 낮은 중국산의 유통을 감소시켜 양질의 국산 생약을 보호할 수 있을 것으로 판단된다.
\end{abstract}

Key words: content criteria, ecdysterone, inokosterone, Achyranthis Radix, HPLC

Corresponding author

Phone : +82-(0)42-821-5928 Fax : +82-(0)42-823-6566

E-mail : kangjss@cnu.ac.kr, woomh@cu.ac.kr 


\section{1. 서 론}

우슬(Achyranthis Radix, Achyranthes Root)은 대한 약전에는 비름과(Amaranthaceae)의 쇠무릎 Achyranthes japonica Nakai 또는 우슬 A. bidentata Blume의 뿌리 로, 일본약전에는 A. fauriei Leveille et Vaniot 또는 $A$. bidentata Blume의 뿌리로, ${ }^{2}$ 중국약전에는 A. bidentata Blume의 마른 뿌리로 규정되어 있다. ${ }^{3}$ 민간에서 약초 로 사용되는 원식물은 전국의 산야에서 자생하고 있 고 중남부 지역인 전남 장흥, 강진, 고흥, 안동등지에 서 일부 재배되고 있다. 우슬은 겨울철에 잎이 시들어 갈 때 채취하고 잔뿌리를 없애고 작은 묶음으로 묶어 건조시키고 묶음의 윗부분을 잘라내고 다시 말린 것 을 쓴다. 이 생약은 가늘고 긴 원주형의 주근 또는 곁 뿌리가 달린 주근이며 근두는 약간의 근경이 붙어 있 든가 또는 제거되어 있다. 바깥면은 회황색 또는 황갈 색이며 많은 세로 주름과 드문드문 곁뿌리의 자국이 있다. 냄새가 거의 없고 맛은 달며 점액성이다. ${ }^{1,4}$ 우리 나라에서는 우슬의 변종인 쇠무릎 또는 우슬 뿌리의 건조품을 정품으로 인정하고 있으나 중국에서는 우슬 뿌리의 건조품을 정품으로 인정하며 이것을 회우슬로 부르고 있으므로 우리나라의 우슬과 중국의 회우슬의 원식물은 동일하다. ${ }^{3}$ 한편 중국의 약제 시장에서는 회 우슬 뿐 아니라 천우슬(川牛膝, Cyathula officinalis의 뿌리), 마우슬(麻牛膝, Cyathula capitata의 뿌리), 홍우 슬(紅牛膝, Cyathula capitata의 뿌리), 대만산 토우슬 (土牛膝, Achyranthes obtusifolia, A. rubrofusca 및 A. longifolia의 뿌리), 운남성산 백우슬(白牛膝, 패랭이꽃 과 Cucubalus baccifer의 뿌리), 호북성산 미슬(未膝, 쥐꼬리망초과 Strobilanthes nemorusus의 뿌리) 등도 유통되고 있으므로 주의를 요한다. 우슬은 한방에서 구어혈, 통경, 이뇨, 관절통의 개선 등의 목적으로 사 용하는데 월경불순과 악혈(亞血)을 제거하는 요약으로 요슬, 관절의 어통, 마비, 수종, 요불리(尿不利)에 응용 한다. 특히, 임산부는 낙태위험이 있어 사용을 피해야 한다. ${ }^{4}$ 현대적인 생리활성 검색법에 의해 알려진 우슬 의 효능으로 항산화작용, 5,6 중추신경억제 작용, ${ }^{7}$ 혈압 강하 작용, ${ }^{8}$ 이뇨작용, ${ }^{8}$ 소염작용, ${ }^{9-11}$ 항암작용, ${ }^{12-14}$ 면 역기능 조절 작용, ${ }^{15,16}$ 항생물 작용, ${ }^{17}$ 파골세포분화 작 용, ${ }^{18}$ 혈액순환작용 ${ }^{19}$ 등이 보고되었다.

우슬은 과거로부터 민간약으로 가장 많이 이용되는 것 중의 하나이나 산지, 기원식물, 가공저장법에 따른 품질 평가기준이 모호하여 과학화된 성상 및 성분함량 의 객관적 표준화가 필요하다. 우슬로부터 ecdysteroid
로 ecdysterone, ${ }^{20}$ hydroxyecdysterone, ${ }^{21}$ inokosterone,${ }^{20}$ ponasteroside $\mathrm{A}$, polypodine $\mathrm{B}^{20}$ 등이, 알칼로이드로 achyranthine $^{22}$ 등이, steroid로 $\beta$-sitosterol, stigmasterol, rubrosterone ${ }^{4}$ 등 및 수종의 saponin 성분이 알려져 있다 .23 우슬 중의 다양한 생리활성 성분은 자외-가시부검출 법, ${ }^{24}$ 광다이오드어레이 검출법(DAD), ${ }^{25}$ 증기화광산란검 출법(ELSD) ${ }^{26}$ 전기분무이온화법 ${ }^{26}$ 등의 검출법을 이용 한 고속액체크로마토그래피법 또는 모세관전기영동법을 이용하여 분석한 예가 보고되었다. ${ }^{27}$ 대한약전과 일본약 전에는 우슬의 지표성분 함량이 설정되어 있지 않고, 중 국 약전에는 ecdysterone의 함량이 $0.03 \%$ 이상으로 기준 을 설정하고 있다. 대한약전에는 ecdysterone을 표준품으 로 사용한 TLC 확인시험 및 거품시험을 하고 있으며, 일본약전에서는 분말을 이용하여 지속성의 미세한 거품 확인시험을 하고 있다. 현재 한국에서 유통되는 우슬에 대한 기준을 중국 약전의 기준을 적용할 수 있을지는 알 수 없으므로 이에 대한 모니터링이 필요하다. 본 연 구에서는 현재 한국 및 중국시장에서 유통되고 있는 우 슬을 다양한 지역에서 수집하고 이들로부터 성분 중 가 장 함량이 높은 것으로 알려진 ecdysterone과 inokosterone을 지표물질로 하여 이들의 함량 분포를 구하여 통계적인 방법으로 우슬의 효율적인 품질관리를 위한 합리적인 함량기준을 설정하고자 하였다.

\section{2. 실험방법 및 재료}

\section{1. 기기 및 시약}

연구에 사용한 HPLC system은 CBM-10A system controller, LC-10AD 펌프, SPD-10A UV 검출기, CTO$10 \mathrm{~A}$ 주입기(Shimadzu, Kyoto, Japan)를 사용하였고, Optimapak C18 (4.6×250 mm, RStech, Korea)를 사용 하였다. 분리된 성분의 확인을 위한 $\mathrm{LC} / \mathrm{MS}$ 는 $\mathrm{API}$ 3200QTRAP LC-MS/MS system (AB SCIEX, USA)를 사용하였다. 표준품으로 ecdysterone과 25(S)-inokosterone 을 식약청으로부터 제공받았다. HPLC에 사용한 용매 는 모두 HPLC용으로 SK Chemical (Korea)에서 구입 하였고, 개미산과 내부표준물질로 사용된 syringic acid는 Sigma사(MI, USA)에서 구입하였다. 시료 추출 을 위한 용매는 모두 특급 및 일급시약을 사용하였다. 3차 증류수의 제조에는 Milli-Q Apparatus (Millipore, $\mathrm{MA}, \mathrm{USA}$ )를 사용하였다.

\section{2. 시료의 수집}

2010년 3월부터 12 월까지 중국 및 한국의 각 지역 
으로부터 93점(1001 30, 2001 63)의 시료를 구입하였 고 그 중 위품으로 확인된 6점을 제외한 87점의 시료 를 실험에 사용하였다. 위품으로 확인된 시료는 마우 슬 1점(1030), 천우슬 5점(1025, 2018, 2020 21, 2062) 이었고, 정품인 87 점의 시료의 산지는 한국 28 점, 중 국 54점, 산지미상 5점이었다. 시료는 동국대학교 한 의과대학 이제현교수가 감별하였고, 증거표본은 충남 대학교 약학대학에 보관하였다.

\section{3. 검액 및 표준액의 제조}

지표물질의 분석을 위하여 시료를 분말로 한 후 50 $\mathrm{mL}$ 의 마개달린 시험관에 넣고 $50 \%$ 에탄올 $20 \mathrm{~mL}$ 를 가했다. 시험관을 상온의 초음파 추출기에 장착하고 90 분간 추출한 후 $3,000 \mathrm{rpm}$ 으로 5 분간 원심분리하 였다. 상등액 $500 \mu \mathrm{L}$ 를 취하여 내부표준품으로 $350 \mathrm{ppm}$ 의 syringic acid $100 \mu \mathrm{L}$ 를 가한 후 0.22 $\mu \mathrm{m}$ 막여과기로 여과한 액을 검액으로 하였다. 우슬 의 지표성분인 ecdysterone과 inokosterone 표준품을 $\mathrm{HPLC}$ 에 의하여 순도를 확인하였고 각각 $98.43 \%$ 와 $96.13 \%$ 의 순도를 나타내었다. 검 량선 작성을 위한 표준액은 ecdysterone과 inokosterone을 메탄올에 녹 여 $1 \mathrm{mg} / \mathrm{mL}$ stock solution으로 하고 단계별로 희석 하여 사용하였다.

\section{4. 크로마토그래피 분석 및 밸리데이션}

기존의 문헌에 제시된 방법과 예비실험을 거쳐 크 로마토그래피 조건을 설정하였다. 이동상은 $0.08 \%$ 개 미산용액-아세토니트릴(85:15. v/v) 혼합액으로 하여 1 $\mathrm{mL} / \mathrm{min}$ 의 속도로 흘려 주었다. 주입량은 $30 \mu \mathrm{L}$ 로 하 여 UV $254 \mathrm{~nm}$ 에서 검출하였다. 컬럼의 온도는 $30{ }^{\circ} \mathrm{C}$ 로 하였다. 분석법은 ICH guideline에 의하여 우슬의 지표성분의 검량선으로부터 직선성을 검토하고, 반복 측정의 결과로부터 일내 및 일간 정밀도를 검토하였 으며, 그 외 정확도와 선택성, 정량범위, 회수율을 결 정 하였다. 분리된 성분의 확인을 위하여 $\mathrm{LC} / \mathrm{MS}$ 를 사용하였고, 분석 조건은 양이온 모드에서 분무가스유 속 $50 \mathrm{~L} / \mathrm{min}$, Ion source 온도 $600{ }^{\circ} \mathrm{C}$, 검출기 전압 $2.0 \mathrm{kV}$ 였다.

\section{5. 함량기준치 설정}

성분함량기준치를 설정하기 위하여 이용된 방법으 로는 상대표준편차에 따른 신뢰구간을 이용한 방법 (표준편차법), ${ }^{28}$ 로그함량과 백분위수에 대한 회귀직선 모형으로의 분석법(회귀직선법)을 이용하였다. ${ }^{29}$ 표준

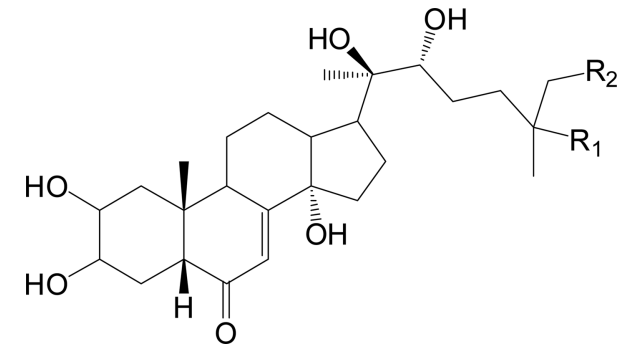

Fig. 1. Chemical structures of marker compounds for ecdysterone $\left(\mathrm{R}_{1}=\mathrm{OH}, \mathrm{R}_{2}=\mathrm{H}\right)$ and inokosterone $\left(\mathrm{R}_{1}=\mathrm{H}\right.$, $\left.\mathrm{R}_{2}=\mathrm{OH}\right)$.

편차법은 \%RSD의 값 50 을 기준으로 신뢰구간을 설 정하여 함량기준치를 도출하였으며, 50 이하(또는 초과) 인 경우에는 전체 자료값들의 평균 $(\mathrm{m})$ 과 표준편차(s) 에 대하여 구간 $\mathrm{m} \pm 1.645 \mathrm{~s}$ (초과의 경우 $\mathrm{m} \pm \mathrm{s}$ ) 안의 값 만 취한 후 구간내의 자료값들의 평균 $\left(\mathrm{m}^{\prime}\right)$ 과 표준편차 (s')에 대하여 함량기준치로 m'-1.96s'(초과의 경 우 m'$\left.1.645 \mathrm{~s}^{\prime}\right)$ 으로 산출하였다. 회귀직선법은 성분함량의 로 그값(로그함량)을 $\mathrm{x}$ 값으로 하고 대응되는 백분위수(누 적분포함수값)를 y값으로 하는 scatter plot에서 모형의 설명력인 결정계수 $\mathrm{R}^{2}$ 의 값이 이상일 때의 적합된 회 귀직선의 방정식이 $y=\beta_{0}+\beta_{1} x$ 일 경우 함량기준치로서 $\mathrm{e}^{-\beta_{0} \beta_{1}}$ 를 산출하였다. 조건이 만족되지 않을 경우에는 보정절차에 의하여 함량기준치를 산출하였다.

\section{3. 결과 및 고찰}

\section{1. 성분분석 및 선택성}

Fig. 2에서 나타난 바와 같이 내부 표준물질로 사용 된 syringic acid, 우슬의 지표성분인 ecdysterone 및 inokosterone의 머무름 시간은 각각 9.8분, 24.6분, 33.1 분이었고, ecdysterone 및 inokosterone과 가장 인 접한 성분과의 분리도는 각각 5.1 및 3.9 로 지표물질 이 추출물의 다른 성분들로 부터 간섭을 받지 않고 양호하게 분리되었다. 각각의 피크로부터 계산된 이론 단수의 평균은 약 18,000 단으로 컬럼의 효율이 충분 히 큰 것으로 나타났다. LC-MS를 이용하여 시료에서 분리된 성분의 분자량을 확인하였을 때 1 번과 2 번 피 크로부터 분자량 480 인 ecdysterone과 inokosterone의 $[\mathrm{M}+\mathrm{H}]^{+}$및 $[\mathrm{M}+\mathrm{Na}]^{+}$에 해당하는 $\mathrm{m} / \mathrm{z}=481$ 및 503 이 관찰되었다. 두 물질은 이성질체로 $\mathrm{MS}$ 스펙트럼만으 로는 두 물질을 동정할 수는 없으나 두 개의 피크가 ecdysterone과 inokosterone에 해당한다는 사실을 알 수 있었다(Fig. 3). 

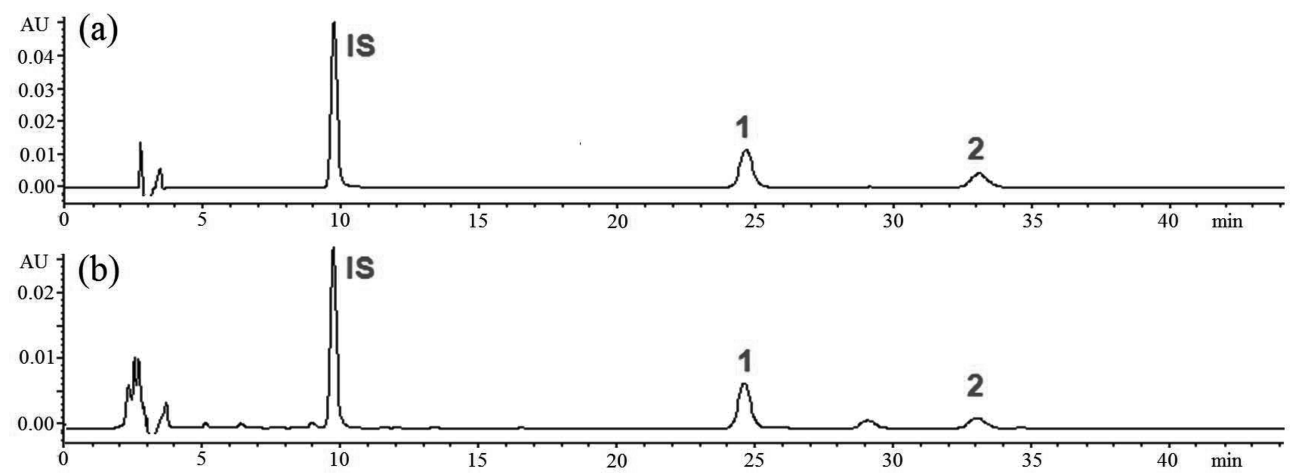

Fig. 2. Chromatograms of (a) standard mixture and (b) Achyranthis Radix extract. Chromatographic conditions: mobile phase: $15 \%$ acetonitrile containing $0.08 \%$ formic acid, flow rate: $1.0 \mathrm{~mL} / \mathrm{min}$, detection: UV $254 \mathrm{~nm}$. Peak identification: 1 . ecdysterone, 2. inokosterone, IS. syringic acid.
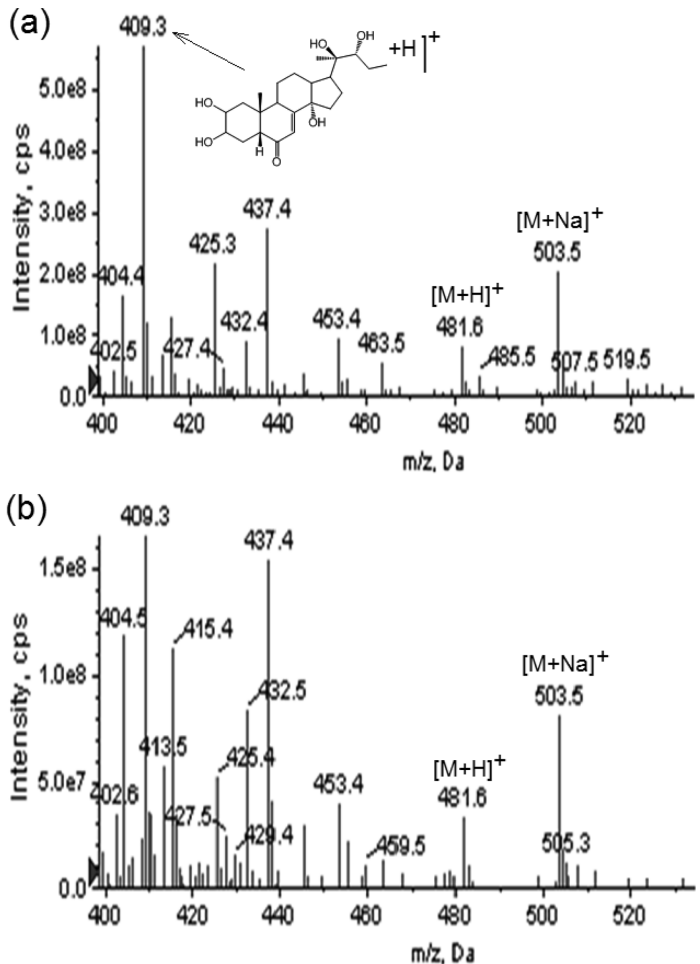

Fig. 3. LC-MS spectra of separated (a) peak 1 and (b) peak 2 in positive mode, representing ecdysterone and inokosterone, respectively.

\section{2. 직선성 및 정량한계}

성분 ecdysterone과 inokosterone은 2 30 $\mu \mathrm{g} / \mathrm{mL}$ 범 위 에서 상관계수 0.99 이상의 양호한 직선성을 나타내었고, 두 가지 성분에 대한 검량선의 식은 각각 $y$ (성분과 IS 의 피크 면적비 $)=0.0262 x($ 농도, $\mu \mathrm{g} / \mathrm{mL}), y=0.0125 \mathrm{x}$ 로
나타났다. 본 실험법에서 검출한계(신호 대 잡음비 $=3$ ) 및 정량한계 $($ 신호 대 잡음비 $=10)$ 는 ecdysterone의 경우 각각 $0.1 \mu \mathrm{g} / \mathrm{mL}$ 및 $0.3 \mu \mathrm{g} / \mathrm{mL}$ 였고, inokosterone의 경 우 각각 $0.2 \mu \mathrm{g} / \mathrm{mL}$ 및 $0.7 \mu \mathrm{g} / \mathrm{mL}$ 로 추출물의 함량분 석에 충분한 것으로 나타났다.

\section{3. 회수율}

균질한 검체 분말을 추출, 원심분리, 여과 등 전처 리 조작을 거치는 동안 지표성분의 회수율을 검토하 기 위하여 표준물 첨가법에 의한 분석결과로부터 구 하였다. 최종 검액 중 첨가한 표준물의 농도가 대조검 체의 ecdysterone에 대하여 최고 농도의 $13.3 \%, 40 \%$, $80 \%$ 가 되게 한 $3 \mathrm{batch}$ 의 검액과 대조검체로 표준물 을 첨가하지 않은 검체를 분석하여 회수율을 구한 결과 는 Table 1에서 볼 수 있는 바와 같이 $98.7 \%$ 103.0\%로 우수하게 나타났다.

\section{4. 정밀도 및 정확도}

전 분석과정을 통한 분석결과의 일내 및 일간의 정 확도와 정밀도는 지표성분의 표준물질을 농도가 각각 다른 세 가지 농도로 첨가한 검체를 분석하여 구한

Table 1. Recovery test of ecdysterone through standard addition method $(\mathrm{n}=5)$

\begin{tabular}{ccc}
\hline \hline $\begin{array}{c}\text { Fortified conc. } \\
(\mu \mathrm{g} / \mathrm{mL})\end{array}$ & $\begin{array}{c}\text { Observed conc. } \\
(\mu \mathrm{g} / \mathrm{mL})\end{array}$ & $\begin{array}{c}\text { Mean recovery } \\
(\%)\end{array}$ \\
\hline 0.00 & $13.04 \pm 0.05$ & - \\
4.00 & $16.99 \pm 0.03$ & 98.7 \\
12.00 & $24.92 \pm 0.06$ & 99.0 \\
24.00 & $37.76 \pm 0.17$ & 103.0 \\
\hline
\end{tabular}


Table 2. Precision and accuracy of analytical results

\begin{tabular}{cccccccc}
\hline \hline \multirow{2}{*}{ Compounds } & $\begin{array}{c}\text { Spiked conc. } \\
(\mu \mathrm{g} / \mathrm{mL})\end{array}$ & $\begin{array}{c}\text { Observed } \\
(\mu \mathrm{g} / \mathrm{mL})\end{array}$ & $\begin{array}{c}\text { Precision } \\
(\%)\end{array}$ & $\begin{array}{c}\text { Accuracy } \\
(\%)\end{array}$ & $\begin{array}{c}\text { Observed } \\
(\mu \mathrm{g} / \mathrm{mL})\end{array}$ & $\begin{array}{c}\text { Precision } \\
(\%)\end{array}$ & $\begin{array}{c}\text { Accuracy } \\
(\%)\end{array}$ \\
\hline \multirow{3}{*}{ Ecdysterone } & 2.00 & 2.00 & 2.04 & 100.08 & 2.00 & 1.87 & 99.91 \\
& 10.00 & 9.13 & 0.49 & 91.34 & 9.31 & 0.94 & 93.06 \\
& 30.00 & 31.38 & 0.58 & 104.59 & 31.31 & 1.36 & 104.38 \\
\hline \multirow{2}{*}{ Inokosterone } & 2.00 & 1.67 & 3.41 & 83.45 & 1.65 & 0.99 & 82.64 \\
& 10.00 & 9.18 & 0.87 & 91.77 & 9.12 & 1.38 & 91.22 \\
& 20.00 & 19.85 & 1.33 & 99.25 & 20.26 & 1.58 & 101.29 \\
\hline
\end{tabular}

Table 3. Content (\%) of ecdysterone and inokosterone in Achyranthis Radix collected from Korea and China

\begin{tabular}{|c|c|c|c|c|c|c|}
\hline & \multicolumn{3}{|c|}{ Ecdysterone } & \multicolumn{3}{|c|}{ Inokosterone } \\
\hline & Mean & SD & Range & Mean & SD & Range \\
\hline Korea & $0.105^{*}$ & 0.033 & $0.04 \sim 0.15$ & $0.066^{*}$ & 0.020 & $0.02 \sim 0.11$ \\
\hline China & 0.059 & 0.015 & $0.02 \sim 0.11$ & 0.035 & 0.009 & $0.015 \sim 0.07$ \\
\hline Total & 0.074 & 0.031 & $0.02 \sim 0.15$ & 0.045 & 0.020 & $0.015 \sim 0.11$ \\
\hline
\end{tabular}

${ }^{*} \mathrm{p}<0.001$ when compared with Chinese samples.

Table 4. Content criteria of the marker compounds and the pass-rate of samples by various evaluation methods

\begin{tabular}{lcccccrrr}
\hline \hline \multirow{2}{*}{ Evaluation methods } & \multicolumn{2}{c}{ Content criteria(\%) } & & \multicolumn{3}{c}{ Pass-rate of samples(\%) } \\
\cline { 2 - 3 } & Ecdysterone & Inokosterone & & Korean & & Chinese & Total \\
\hline Chinese pharmacopoeia & 0.030 & - & & 100.0 & 94.4 & 92.6 \\
Standard deviation & 0.020 & 0.011 & & 100.0 & 100.0 & 100.0 \\
Linear regression & 0.033 & 0.020 & & 100.0 & 92.6 & 95.4 \\
\hline
\end{tabular}

결과 값으로부터 계산하였다. Table 2에서 제시한 바와 같이 정확도는 일간 및 일내를 통틀어 82.64 104.59\% 로 나타났다. 정밀도는 일간 일내 모두 $3.4 \%$ 이하로 양호하였다.

\section{5. 표준액의 안정성 및 분석법의 완건성}

우슬의 분석에 사용된 표준액의 안정성을 확인하기 위하여 메탄올에 녹인 표준액을 실온과 냉장 $\left(4{ }^{\circ} \mathrm{C}\right)$ 에 서 15 일간 관찰하였다. 관찰기간 동안 실온과 냉장 모 두에서 함량의 차이가 없었으며 특정한 성분이 나타 나지도 않았다. 또한 다른 회사에서 판매되는 동일 종 류의 컬럼을 이용하여 서로 다른 온도에서 실험하여 본 분석법의 완건성을 확인하였을 경우 이론단수, 용량 인자, 분리인자, 성분의 분리도 및 함량에서 유의한 차 이가 관찰되지 않아 완건성이 우수함을 알 수 있었다.

\section{6. 우슬 지표성분의 함량분석 및 기준함량 설정}

확립된 $\mathrm{HPLC}$ 분석조건으로 정품 87점의 우슬시료
를 분석하였다. ecdysterone과 inokosterone은 각각 $0.074 \%, 0.045 \%$ 의 함량을 보였으나 국산 28 점과 중국 산 54점을 따로 분리하여 계산했을 경우 두 가지 지 표성분에 대해 국산의 평균함량이 중국산의 평균함량 에 비해 ecdysterone은 약 1.8배, inokosterone은 약 1.9 배 높았으며, 평균함량의 차이는 통계적으로 유의한 것으로 나타났다. 표준편차법을 이용하였을 경우 edcysterone과 inokosterone의 함량기준은 각각 $0.02 \%$, $0.011 \%$ 로 계산되었는데, 이 값은 모니터링에 사용된 시료 함량의 최솟값보다 낮아 이 기준을 사용하면 모 든 시료가 시험에 합격하는 것으로 나타났다. 따라서, 우슬의 경우 기준 설정 시 표준편차법은 효용성이 떨 어질 것으로 판단된다. 회귀직선법을 이용하였을 경우 ecdysterone은 $0.033 \%$, inokosterone은 $0.020 \%$ 로 계산 되는데 이 값을 함량기준으로 하였을 경우 전체 시판 품의 약 $95.4 \%$ 가 합격 되는 것으로 나타났다. 한국, 중국 및 일본의 공정서에는 inokosterone 기준함량은 설정되어 있지 아니하고, 중국약전에는 ecdysterone이 
$0.03 \%$ 로 설정되어 있다. 모니터링의 결과를 기초로하 여 ecdysterone의 기준을 $0.033 \%$ 로 상향 조정하고, inokosterone의 기준함량을 $0.02 \%$ 로 설정하는 경우 국 산은 모두 합격하였고, 중국산의 $92.6 \%$ 가 합격되는 것으로 나타났다. 결론적으로, 우슬 중 지표물질인 ecdysterone의 함량을 $0.033 \%$, inokosterone의 함량을 $0.020 \%$ 로 설정함므로써 성분함량이 낮은 중국산 약재 의 유통을 감소시키고 국산 약재를 보호할 수 있을 것으로 판단된다. 또한, 우슬의 품질관리에 새로운 기 준을 적용하므로써 우수한 약재의 유통을 유도할 수 있을 것으로 본다.

\section{4. 결 론}

본 연구에서는 HPLC-UV를 이용하여 한국 및 중국 의 각 지역에서 수집된 93점의 우슬 시료에 대한 ecdysterone 및 inokosterone의 함량모니터링을 실시하 였다. 기준의 설정방법으로 표준편차법을 이용하였을 때보다 회귀직선법을 이용하였을 경우에 보다 합리적인 기준설정이 가능하였으며, ecdysterone 및 inokosterone의 함량 기준은 각각 은 $0.033 \%$, 및 $0.020 \%$ 로 계산되었 다. 새로 설정된 기준으로 시판 우슬의 품질을 평가하 였을 경우 국산은 모두가 합격하였고 중국산은 $92.6 \%$ 가 합격하여 전체적 합격률은 $95.4 \%$ 였다. 새로운 기 준은 지표성분의 함량이 낮은 중국산의 유통을 감소 시켜 양질의 국산 생약을 보호할 수 있을 것으로 판 단된다.

\section{감사의 글}

본 연구는 식품의약품안전청 한약재과학화사업의 지원으로 수행되었으며 이에 감사드립니다.

\section{참고문헌}

1. Korea Food and Drug Administration, Korean Pharmacopoeia IX, Seoul, p.958, 2007.

2. The Minister of Health, Labour and Welfare of Japan, Japanese Pharmacopoeia 15 Ed., p. 1268, 2006.

3. Chinese Pharmacopoeia Commission, Pharmacopoeia of the People's Republic of China, p.67, 2010.

4. Korea Pharmacognosy Soc., Pharmacognosy, Dongmyungsa, p.166, 2010.

5. H. S. Choi, M. J. Lee, M. S. Na, M. Y. Lee and D. B.
Choi, J. Ind. Eng. Chem., 15(2), 275-280 (2009).

6. F. Wang, T. Ogata and I. Tomohiro, Technol. Med., 2(1), 24-28 (2009).

7. U. Bhosale, R. Yennanarayan, P. Prachi, M. Zambare and R. S. Somani, Annals. Neurosci., 18, 44-47 (2011).

8. N. C. Neogi, R. D. Garg and R. S. Rathor, Indian J. Pharm., 32(2), 43-6 (1970).

9. S. B. Han, C. W. Lee, Y. D. Yoon, J. H. Lee, J. S. Kang, K. H. Lee, W. K. Yoon, K. Lee, S. K. Park and H. M. Kim, Arch. Pharm. Res., 28(8), 902-8 (2005).

10. T. Lu, C. Mao, L. Zhang and W. Xu, Zhong Yao Cai, 20(10), 507-9 (1997).

11. Y. O. Kim, S. W. Lee and S. E. Lee, Kor. J. Med. Crop., 17(6), 470-4 (2009).

12. S. Yu, Y. Zhang, Zhonghua Zhong Liu Za Zhi, 17(4), 275-8 (1995).

13. D. B. Xiang and X. Y. Li, Zhongguo Yao Li Xue Bao, 14(6), 556-61 (1993).

14. X. M. Chen and G. Y. Tian, Carbohydr. Res., 338(11), 1235-41 (2003).

15. S. D. Lee and K. S. Kim, J. Kor. Acup. Mox. Soc., 16(3), 287-315 (1999).

16. W. S. Do, K. H. Kim and K. S. Kim, J. Kor. Acup. Mox. Soc., 18(1), 157-169 (2001).

17. S. M. Jung, S. I. Choi, S. M. Park and T. R. Heo, Kor. J. Food Sci. Technol., 39(5), 564-8 (2007).

18. J. H. Kim, J. Y. Ki, J. Y. Ann, H. J. Park, H. J. Kim, H. B. Kwak, J. M. Oh and Y. K. Kim, Kor. J. Herbol., 25(1), 65-74 (2010).

19. F. Xie, X. Li, Sun. K, Y. Chu, H. Cao, N. Chen, W. Wang, M. Liu, W. Liu and D. Mao, J. Tradit. Chin. Med., 21(3), 225-31 (2001).

20. J. Li, H. J. Li, P. Li and H. Qi, Biomed. Chromatogr., 21(8), 823-828 (2007).

21. K. H. Son, J. H. Hwang, S. H. Lee, J. H. Park, S. J. Kang, S. Y. Chang and K. S. Lee, Kor. J. Pharmacogn., 30, 335-339 (1999).

22. Ratra, S. Parminder, Curr. Trends. Life Sci., 4(Adv. Ecol.), 81-5 (1979).

23. M. F. Marcone, F. Jahaniaval, H. Aliee and Y. Kakuda, Food Chem., 81, 7-12 (2003).

24. S. Ogawa, A. Yoshida and K. Reiko, Chem. Pharm. Bull., 25(5), 904-8 (1977).

25. J. Li, H, Qi, L. W. Qi, L. Yi and P. Li, Anal. Chim. 
Acta., 596(2), 264-272 (2007).

26. J. Li, P. Li, H. J. Li, Y. Song, Z. M. Bi and Y. J. Li, J. Sep. Sci., 30(6), 843-850 (2007).

27. X. H. Ding, Fenxi Ceshi Xuebao, 19(5), 53-55 (2000).
28. Korea Food and Drug Administration, Guidelines for the establishment of concentration limit for crude drugs, Seoul, 2007.

29. J. S. Kang and Y. S. Jang, Korea patent, 10-2011-0030475. 